\title{
La literatura de mujeres como archivo hospitalario: una propuesta
}

\author{
MÓNICA SZURMUK Universidad de Buenos Aires - CONICET, Argentina / monicaszurmuk@gmail.com \\ ALEJANDRO VIRUÉ Universidad Nacional de San Martín, Argentina / alejandrovirue@gmail.com
}

\section{Resumen}

En este trabajo analizaremos el aporte específico de la literatura en la recuperación y la construcción de la historia de las mujeres. A partir de las reflexiones de Jaques Derrida, proponemos el concepto de archivo hospitalario para pensar no solo la selección de un corpus sino una forma de abordarlo desde las teorías del presente, ya sea para, desde la crítica, dar cuenta de aquello que en ese corpus aparece apenas sugerido o de manera cifrada; ya sea para recrear, desde la ficción, imágenes que dialoguen y expandan ciertos tópicos que, en el contexto de su producción, pudieron resultar extemporáneos o impensables. Desde esta perspectiva analizaremos obras de Sor Juana Inés de la Cruz (y su actualización en una performance de Jesusa Rodríguez), Sabina Berman, Lina Beck-Bernard y Tununa Mercado.

Palabras clave: archivo hospitalario / Sabina Berman / literatura de mujeres / Derrida / Sor Juana Inés de la Cruz

\section{Women's Literature as Hospitable Archive: A Proposal \\ Abstract}

In this article, we analyze the specific contributions of literature in the reconstruction of the presence of women in history. Drawing from Jacques Derrida, we propose the concept of hospitable archive to account for the selection of a new literary canon. Furthermore through attention to what we call hospitable archive, we put forth novel ways of reading that are attentive to what is suggested or repressed in these texts, and to what could not signify in the context of production and publication, but acquires new life in a contemporary reading. From this perspective we analyze works by Sor Juana Inés de la Cruz (and the actualization of her poetry in Jesusa Rodríguez's performance), Sabina Berman, Lina Beck-Bernard and Tununa Mercado.

Key words: hospitable archive / Sabina Berman / literatura de mujeres / Derrida / Sor Juana Inés de la Cruz

Recibido: 18/10/2019. Aceptado: 26/2/2020

Para citar este artículo: Szurmuk, M. y Virué, A. (2020). La literatura de mujeres como archivo hospitalario: una propuesta. El taco en la brea, 11 (diciembre-mayo), 67-77. Santa Fe, Argentina: UNL. DOI: 10.14409/ tb.v1i11.9154 
Un escenario en claroscuro. Un silbido y la neblina representan una estación de tren. Una muchacha joven cruza el andén. Un hombre nos habla de ella: «En la neblina de la una de la mañana del primer día de 1900 vi subir a Dora al tren» (Berman:77). Ya en el vagón, discuten, él le ofrece alquilarle una casa, ayudarla a estudiar, a liberarse de las presiones familiares como hija para transformarse en su amante. Ella se resiste. Se lanza hacia la puerta, él la atrapa por la cintura. El tren entra a un túnel. Mientras el grito de ella se pierde en el aullido del silbato del tren, la luz del escenario se apaga.

La escena proviene de la obra de teatro Feliz nuevo siglo, doktor Freud de la dramaturga mexicana Sabina Berman estrenada en la ciudad de México en el año 2000. La joven protagonista es Dora, la paciente que según Freud interrumpió su tratamiento el 31 de diciembre de 1899. En enero de 1900 Freud escribió el fundacional caso al que años después le agregó una nota al pie: Dora se ha casado con un ingeniero, ha tenido hijos, «ha sido ganada para la vida» (Freud, 1996:27). Sabina Berman infunde vida a la nota al pie y escribe una ficción posible de lo que pasó ese nuevo año y ese nuevo siglo cuando Dora podría haberse creado un destino alternativo que era el que deseaba. ¿Qué le pasó a Dora, pregunta Berman, entre ese día en el que, en el umbral del nuevo siglo, decide abandonar su análisis y esos varios años después cuando ya está casada con un ingeniero, tiene hijos, ha sido "ganada para la vida»?

El feminismo ha ahondado, desde la investigación, la creación y la militancia, en las historias de las mujeres del pasado buscando reconstruir lo que falta en los archivos patriarcales. La literatura particularmente es un archivo hospitalario donde se albergan posibles vidas del pasado y también donde se alojan experiencias a las que podemos revitalizar, oxigenar y darles vida otra vez. La literatura escrita por mujeres tiene un lugar privilegiado en ese archivo, un espacio donde se cobijó históricamente lo que no se podía decir (por censura o por normas de la época, por ejemplo) y también lo que todavía no se podía pensar. Es un espacio textual donde se instalan las inquietudes que aún no pueden nombrarse; es una carta al futuro, esperando una lectura generosa.

Hay dos rutas, por lo menos, para iluminar los intersticios en los que el archivo patriarcal ha condenado a la historia de las mujeres. Una es la investigación histórica, otra es la creación artística y literaria que ha tematizado frecuentemente lo no decible en silencio. Sor Juana Inés de la Cruz hizo del silencio un tropo de su obra. Por ejemplo dice en el poema «Primero Sueño»:

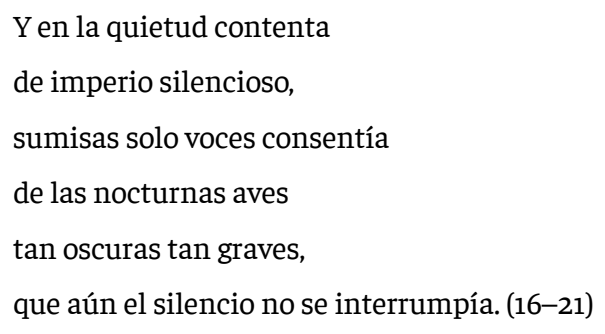

La artista mexicana Jesusa Rodríguez tomó la posta de Sor Juana y en una de sus performances más evocativos recita de memoria los 975 versos del poema. Jesusa aparece en el escenario o entre el público vistiendo un hábito blanco. Mientras recita, se va quitando la ropa, demostrando al hacerlo la complicada hermenéutica del hábito como modo de ocultamiento del cuerpo. Al terminar queda completamente desnuda y ya sin palabras. Como señala Mary Louise Pratt, la performance a la vez parodia las soberbias barrocas del poema y realiza su promesa al infundirle una vida que 
no era posible en el momento en que el poema fue escrito (559). La desnudez de Jesusa resalta el modo en que Sor Juana desnuda su psiquis y su alma y a la vez parodia el gesto intrincado y barroco presente en el exceso de forma y en el exceso de ropa. El recitado del poema une dos modos de presencias culturales y literarias de mujeres en América Latina, en el siglo XVI y el XXI y le otorga una continuidad artificiosa pero ideológicamente promisoria a la presencia de las mujeres en la cultura de la región.

Tanto el poema original de Sor Juana como la performance de Jesusa juegan con el como si. El poema recoge el deseo de conocer, de asir el mundo. El travestismo de Sor Juana del que han hablado muchas críticas feministas viste el entendimiento y disfraza el sitio del conocimiento a través del hábito, del encierro en el convento y del cambio del lugar de enunciación. Sor Juana navegaba las tretas del débil, como afirma Josefina Ludmer, haciendo ciencia desde la cocina, habitando el espacio que la sociedad le asignaba y transformándolo (Ludmer:47-54). El texto, como el hábito, ocultaba el cuerpo. Jesusa toma este texto extraordinario y lo interviene devolviéndole el cuerpo; al devolver el cuerpo a la escena Jesusa también les da presencia a la monja y a la escritora.

Elegimos comenzar con dos figuras centrales de la cultura: Dora como la figura a través de la cual se construye una versión hegemónica de la sexualidad femenina, Sor Juana como la escritora fundacional de la literatura latinoamericana. Y las leímos a ambas a través de intervenciones culturales contemporáneas y feministas. Buscamos a través de algunos ejemplos contestar las siguientes preguntas: ¿cuál es el espacio de la literatura en la recuperación y la construcción de la historia de las mujeres?; ¿qué tipo de aportes hace la crítica literaria a la historia de las mujeres?

En este artículo usamos el concepto de archivo hospitalario como herramienta de lectura y visibilización de producciones textuales aminoradas por su autoría (mujeres, disidentes sexuales, poblaciones subalternizadas) o por haber sido escritas en lenguas menores. Proponemos que la literatura puede funcionar como un archivo hospitalario en el que se preservan y multiplican las posibilidades de creación, recreación y materialización de memorias alternativas.

Teniendo esto en cuenta, concebimos el archivo hospitalario de dos modos:

a) como la selección de un corpus que, por haber sido creado por autores y autoras relegados en razón de su género, grupo étnico u orientación sexual, alberga de manera figurada información relevante sobre la historia y las condiciones del grupo en cuestión;

b) como un modo de abordaje crítico específico de esos textos, ya sea para dar nombre, desde las teorías del presente, a aquello que en ese corpus aparece apenas sugerido o de manera cifrada; ya sea para recrear, desde la ficción, imágenes que dialoguen y expandan ciertos tópicos que, en el contexto de su producción, pudieron resultar extemporáneos o impensables.

En lo que sigue desarrollaremos, siguiendo fundamentalmente algunas reflexiones de Jaques Derrida, nuestro modo de entender el archivo hospitalario, para luego ofrecer algunos ejemplos que pongan en acto el trabajo sobre ese archivo.

\section{Archivo hospitalario: una propuesta}

En las últimas décadas, el concepto de archivo dejó de ser un tema exclusivo de bibliotecólogos y funcionarios de las instituciones destinadas a su conservación para convertirse en objeto de debate de las disciplinas humanísticas y las ciencias sociales en general. Esto se debe, en parte, a los 
drásticos cambios que la digitalización produjo tanto en la producción como en la conservación y selección de los documentos archivables, pero también a cierta sospecha generalizada acerca de la naturaleza de los archivos existentes. Como señala Marlene Manoff en Theories of the Archive from Across the Disciplines, esta sospecha se vuelve especialmente fuerte en disciplinas como los estudios poscoloniales y de mujeres (women's studies). En ambos campos se ha puesto el foco en los límites, las ausencias y las distorsiones de los archivos oficiales. En lo que respecta específicamente a los women's studies, Manoff sostiene que una de las maneras de definirlos es, precisamente, «as a project to write women back into the historical record-to fill the gaps and correct the omissions in the archive» (Manoff:15).

Una de las intervenciones clave en este sentido es la que realizó el filósofo Jaques Derrida en su célebre Mal de archivo. Una impresión freudiana, presentado originalmente como conferencia en el marco del coloquio internacional Memory: The Questions of Archives, realizado en Londres en 1994. Allí postula una serie de tesis destinadas a ampliar el concepto de archivo, tarea que juzga fundamental para el fortalecimiento de las sociedades democráticas, al punto de afirmar que «la democratización efectiva se mide siempre por este criterio esencial: la participación y el acceso al archivo, a su constitución y a su interpretación» (48-49).

Para ilustrar a qué refiere Derrida con la expresión mal de archivo comenzaremos con una de las historias que analiza cerca del final de su texto. Se trata de Gradiva, la novela de fines del siglo XIX del alemán Wilhelm Jensen que se volvió célebre por el análisis que realizó Sigmund Freud en Delirios y sueños en la Gradiva de W. Jensen (1907). El protagonista de la historia es el joven arqueólogo Norbert Hanold, quien descubre en el Museo Nacional de Arqueología de Nápoles un bajorrelieve que lo cautiva, al punto de proveerse de una copia en arcilla que lleva a su despacho para estudiar con detenimiento. Valiéndose de todos los recursos de su disciplina, procura crearle una historia a la imagen allí representada: una joven doncella que camina con una pose muy peculiar, en sandalias, apoyando uno de los pies completamente en el piso y manteniendo el otro arqueado, apenas sostenido por la punta. Decide llamarla Gradiva, la que avanza, y la imagina en Pompeya, hija de una casa noble, caminando rumbo al templo de la diosa Ceres. Por los rasgos de su perfil, le atribuye un origen griego. Con este ejercicio, intenta darle sustancia al momento preciso en el que el artista la fijó en su obra. En su estudio, Freud señala que «toda su ciencia sobre la Antigüedad entra paulatinamente al servicio de las fantasías que va tejiendo en torno de la figura que sirvió de original al bajorrelieve» (3). Luego de un sueño que lo conmueve especialmente, en el que presencia el momento del hundimiento de Pompeya bajo la erupción del Vesubio y en el que se encuentra, finalmente, con la joven con la que tanto ha fantaseado, decide viajar a Italia. La novela se convierte así en la búsqueda de las huellas del momento originario que dio lugar a ese archivo. Hanold pretende encontrar en las ruinas de Pompeya un rastro que corrobore la historia que le imaginó al personaje del bajorrelieve.

Derrida diría que Hanold padece mal de archivo. Para dilucidar el sentido de la pieza arqueológica que lo obsesiona, no le basta con aplicar los procedimientos de su disciplina y sus conocimientos sobre la antigüedad. En vez de aproximarse al archivo como lo que es —un registro de un pasado en sí mismo irrecuperable-, pretende usarlo como un medio para alcanzar otra cosa: el momento de su origen, la realidad efectiva que le dio lugar. Aunque este caso es hiperbólico y el personaje, como se ve después en la novela, es víctima de un delirio alucinatorio, el filósofo francés considera que algo de este mecanismo suele ponerse en juego en quienes trabajan con documentos del pasado. 
En vez de ser tomados como un modo peculiar de haber dejado constancia de un acontecimiento, intervenido por el artificio de su autor, las posibilidades del material en el que se asientan y las posteriores interpretaciones que median entre ellos y nosotros, suelen asimilarse a los hechos desnudos. Como si en el archivo radicara la verdad misma, el factum de lo que el pasado tiene para decir. Como si el acceso al archivo pudiera saldar de una vez y para siempre el sentido del pasado.

La producción de archivos, sostiene Derrida, está indudablemente vinculada a la condición finita del ser humano. En este sentido, es un intento por reducir la naturaleza eminentemente efímera de los acontecimientos y sus protagonistas, y como tal, un acto destinado al porvenir. La productividad del archivo radica precisamente en su encuentro con personas de otro tiempo y su sentido es esencialmente inestable: está condicionado por la peculiar transacción entre dos temporalidades. En ese cruce de épocas — la del documento archivado y la de su lector — se produce, inevitablemente, una modificación del archivo a través de la interpretación. Esta interpretación, por su parte, engrosa el archivo, radicalizando su inestabilidad:

Incorporándose al saber que se desarrolla respecto a él, el archivo aumenta, engrosa, gana en auctoritas. Pero pierde al mismo tiempo la autoridad absoluta y meta-textual a la que podría aspirar. Nunca se lo podrá objetivar sin resto. El archivero produce archivo, y es por esto por lo que el archivo no se cierra jamás. Se abre desde el porvenir. (Derrida:38, énfasis en el original)

La naturaleza estructuralmente abierta del archivo inhabilita cualquier pretensión de acceso directo y definitivo al pasado. La novedad que introdujo en el mundo de las ideas la teoría psicoanalítica complejiza aun más las cosas y, en palabras de Derrida, «debería llamar a una revolución al menos potencial en la problemática del archivo» (2, énfasis en el original). Al revelar el universo del inconsciente y sus mecanismos de represión y supresión, la teoría freudiana habilita nuevas posibilidades hermenéuticas en relación con el archivo, que son correlativas a las de sus condiciones de producción. Si la dinámica de la represión resguarda la conciencia del sujeto de ciertos contenidos ominosos, mostrándolos de manera distorsionada, como síntomas, cabe la posibilidad de que buena parte de los contenidos de un archivo signifiquen más que su contenido literal o, incluso, lo desmientan.

Derrida presenta esta idea al discutir las objeciones que el historiador Yosef Hayim Yerushalmi plantea al Moisés y la religión monoteísta de Freud. Yerushalmi sostiene que, si efectivamente el pueblo judío hubiera asesinado a Moisés, como especula Freud, no escondería el hecho (no lo reprimiría) sino que lo narraría "como el ejemplo quintaesencial y extremo del pecado de desobediencia de Israel» (Derrida:36). Derrida acusa a Yerushalmi de suponer que el acto de «archivación» y el de represión proceden de manera independiente, cuando, a su juicio, son parte de uno y el mismo proceso:

La represión es una archivación, es decir, archivar de otro modo (...) y este es todo el problema, distinto de los modos de archivación corriente, consciente, patente; de otro modo, es decir, según las vías que han apelado al desciframiento psicoanalítico. (36)

Si se aplica esta reflexión al origen del archivo, esto es, al momento de su constitución, sería legítimo afirmar que, como la represión, la ficción también archiva de un modo «distinto de los 
modos de archivación corriente, consciente, patente: de otro modo». En su análisis del concepto de archivo, Derrida destaca su etimología ambigua, por derivar del término griego arkhé, que significa tanto comienzo como mandato o norma. El comienzo u origen haría referencia a la cualidad histórica del archivo (su capacidad de dar cuenta de algo que sucedió), pero esta supone una institucionalización: un criterio de selección, un espacio físico de resguardo y sus "guardianes», en el doble sentido de los que lo cuidan y los que tienen el monopolio de su interpretación. Desde la Modernidad, esta tarea ha estado mayoritariamente a cargo del Estado y sus instituciones. En ellos radica no solo el poder de decidir qué merece ser conservado y qué no, sino también las condiciones de acceso y circulación del material y, finalmente, las pautas de interpretación. Estas normas son, sin dudas, coyunturales: están determinadas por el régimen político vigente (no se publica ni se conserva lo mismo en los gobiernos democráticos que en los dictatoriales) y las ideas predominantes de cada época. En esta misma línea, el investigador inglés David Greetham afirma que «all conservational decisions are contingent, temporary, and culturally self-referential, even self-laudatory: we want to preserve the best of ourselves for those who follow» (Manoff:20). Y no atañen solo a la tarea de conservación sino que influyen, también, en la producción de los archivos. Incluso las obras que aparentan haber sido elaboradas según criterios de neutralidad e inclusión están atravesadas por los prejuicios de su tiempo. Greetham cita el caso del The Oxford English Dictionary (OED), considerado el mayor documento léxico de la historia de la lengua inglesa. A su juicio, la entrada de la palabra «mujer» hubiera sido completamente diferente de haber incluido citas de Mary Astell, Fanny Burney, Mary Wollstonecraft, entre otras escritoras mujeres, en vez de basarse exclusivamente en las de Fielding, Congreve, Wordsworth y Byron.

Este ejemplo es especialmente pertinente para introducir la idea de un archivo hospitalario en el que la literatura jugará un rol central. Como señalamos antes, siguiendo el paralelismo con el aparato psíquico tal como lo postula Freud, la literatura, como la represión, archiva de otro modo. Y aunque no sean completamente analogables, sin duda hay una relación en las maneras en que lo hacen. Así como el síntoma, en el caso del individuo, y la desfiguración cifrada o la metáfora, en el caso de un texto, pueden ser el sustituto ficticio de un suceso reprimido, el trabajo de la ficción, en su afán de dar cuenta del presente, puede seguir el camino inverso: desfigurar para evitar la represión, disimular para sortear las normas que rigen lo que los «guardianes del archivo» admiten como conservable. Desde esta óptica pueden analizarse, por ejemplo, el tropo del silencio en el poema «Primero sueño» de Sor Juana Inés de la Cruz, y más acá, la historia de un escritor en ciernes que se propone recuperar el vínculo con su tío para narrar, de otro modo, la represión de la última dictadura militar argentina, como hace Ricardo Piglia en Respiración Artificial.

En su análisis de Freud's Moses. Judaism Terminable and Interminable, de Yerushalmi, Derrida hace especial hincapié en el último capítulo del libro. A diferencia de la primera parte, donde el historiador se aboca a un estudio tradicional de la historia de la teoría psicoanalítica, siguiendo las pautas del trabajo historiográfico, en este realiza un ejercicio ficticio al que llama Monólogo con Freud. Allí, Yersuhalmi le habla a Freud en segunda persona, le manifiesta su admiración, le formula una serie de preguntas y especula con sus posibles respuestas. Derrida utiliza este modo inédito de contar la historia del psicoanálisis para legitimar la ficción como archivo histórico, ubicándola en el mismo nivel que los documentos no ficticios. Para esto recurre a la noción de espectro, que más adelante identificará con el momento originario del archivo, irrecuperable como tal, y, por lo tanto, sujeto a las mismas leyes a las que se somete Yerushalmi al imaginar su monólogo 
con Freud. Hacer hablar a un muerto podría juzgarse como un acto, en principio, éticamente reprochable, en la medida en que el otro no podrá responder jamás. Pero Derrida considera injusto decir que en el monólogo Freud no tiene la palabra. Yerushalmi ha dedicado su vida a estudiar la teoría de Freud, se ha detenido en sus intercambios epistolares, sus objetos personales, su archivo. El libro en cuestión, de hecho, presenta por primera vez algunos documentos, como la dedicatoria que el padre de Freud le escribe en la Biblia que le obsequió cuando cumplió treinta y cinco años. Derrida sostiene que en el Monólogo, Yerushalmi «se identifica con él [Freud] interiorizándolo como un fantasma que habla en él antes que él. Le ofrece hospitalidad y llega a confesarle no sin fervor: "usted existe realmente y sigue estando extrañamente presente en mí"» (34). Luego analiza la reacción del fantasma interpelado en el monólogo. Por su condición de muerto es evidente que no puede responder. Pero aun así, dice Derrida, habla:

sin responder dispone de una respuesta, un poco como el contestador automático, cuya voz sobrevive al momento del registro (...) Suponiendo, concesso non dato, que un vivo responde alguna vez de modo absolutamente vivo e infinitamente ajustado, sin el menor automatismo, sabemos en todo caso que una respuesta espectral (así, pues, instruida por una tékhne e inscrita en un archivo) es siempre posible. No habría ni historia, ni tradición, ni cultura sin esta posibilidad. (35)

La operación de Derrida es doble: por un lado, reivindica el monólogo ficticio con Freud como un trabajo legítimo sobre el archivo; por el otro, relativiza la diferencia radical que, en principio, habría entre los diálogos entre vivos con los de un vivo y un muerto. Este doble señalamiento tiene como objetivo, a nuestro juicio, cuestionar la tentación de leer el libro de Yerushalmi como compuesto por dos partes diferenciadas: la rigurosa del inicio, estructurada por las pautas de la disciplina histórica, y la ficticia del final, a la que no se le debería dar el mismo crédito. La conclusión de Derrida es que el trabajo de archivo supone siempre una respuesta espectral - en tanto documento de un pasado de imposible actualización—, pero, a la vez, esta respuesta espectral es siempre posible, se trate de la reconstrucción de una secuencia histórica o de las respuestas de un muerto en un hipotético diálogo en el presente. Son dos modos posibles de intervención sobre el archivo, dos formas diferentes e igualmente legítimas de hacer hablar al espectro.

Si tomamos seriamente la propuesta de Derrida, el recurso a la ficción, por su forma distinta de archivar, no solo es fundamental para reconstruir una imagen del pasado sino también para ofrecer una mirada distinta de ese pasado en el presente. En otras palabras, la ficción es un procedimiento legítimo para trabajar con la literatura y el arte de otra época; es, en definitiva, otro modo de ejercer la crítica.

Teniendo en cuenta, entonces, el carácter esencialmente abierto de todo archivo, pero también los límites que las normas y las ideas vigentes de cada época imponen a su producción y conservación, creemos que dentro del universo de la literatura existen objetos privilegiados para la construcción de un archivo hospitalario. Nos referimos a aquellos textos escritos por autores que, debido a su género, clase, etnia, religión u orientación sexual, ocupan un lugar marginal en los archivos oficiales. La literatura escrita por mujeres tiene un lugar privilegiado en ese archivo, un espacio donde se cobijó históricamente lo que no se podía decir (por censura o por normas de la época) y también lo que todavía no se podía pensar. 
Como hemos sugerido a partir de nuestra lectura de Derrida, la construcción de este archivo no debe limitarse a la selección de un corpus. Es aquí donde el adjetivo hospitalario cobra relevancia. La escritura de mujeres, en tanto producto de un sujeto cuya autoridad como narrador fue puesta en duda, es sin dudas un dispositivo que significa no solo en las oraciones efectivamente escritas sino también en sus sugerencias, incluso en sus silencios. Es un documento que no solo puede sino que debe ser leído más allá de su literalidad. Sus condiciones de producción, como las de cualquier sujeto no hegemónico, implican un cuidado y un artificio extra del que supone cualquier ejercicio de escritura. A la intervención estético-formal se le suma la reflexión sobre lo que se puede y no se puede decir, consciente de que sus obras serán objeto de un doble escrutinio. La hospitalidad radica, entonces, en el modo de abordarlos. Es una tarea de la crítica. Cuando Derrida analiza la orientación al futuro implícita en todo archivo, sugiere que por ser «un movimiento de promesa y de porvenir, no menos de registro del pasado», el archivo «no puede no guardar en él (...) un peso de impensado» (17, el énfasis es nuestro). Una lectura hospitalaria de estos archivos exige, entonces, la búsqueda generosa de aquello impensado que poseen.

\section{Lecturas feministas, archivos hospitalarios, multidireccionalidad}

Nuestros modos de lectura están informados por los debates actuales y hacemos por consiguiente lecturas multidireccionales ${ }^{2}$ en las que superponemos procesos y experiencias similares. En ese sentido, para retomar el ejemplo con el que comenzamos, leemos a Dora a través de versiones contemporáneas de la violencia sexual. En su nota al pie, Freud le escribe a Dora una historia feliz, fiel a los mandatos de su clase y de su época. Sabina Berman en su obra le escribe una historia infeliz. Ambas son ficticias, cambas son verosímiles? La historia de Dora vía Berman forma parte de la genealogía de la infelicidad que propone Sara Ahmed como tarea de intervención feminista y que incluye también la historia de pequeños fracasos que le escribe Berman a Anna Freud en la misma obra. ${ }^{3}$

El grito de Dora en el escenario mientras el tren cruzaba una frontera a la mitad de la noche convoca los gritos de las víctimas de feminicidio en la frontera norte que eran difícilmente escuchados desde la ciudad de México en el año 2000 cuando se estrenó la obra. A través del grito de Dora en el escenario se pueden adivinar otros gritos si hemos sido sensibilizadas a escuchar. El grito de Dora frente a su deshacer (y usamos acá el término de Catherine Clément —166-176-) no se escucha desde este contexto como un reclamo personal sino como un grito colectivo, resignificado a través de una escucha feminista. Podemos pensar este grito también como parte un archivo de la violación, en respuesta a la afirmación de Ariella Azoulay de la imperiosa ausencia y por consiguiente de una necesidad de que existan imágenes de la violación. ${ }^{4}$ En la obra de Berman la violación se registra en el grito, el silbato del tren, el blackout en el escenario.

A mediados del siglo XIX, Lina Beck-Bernard, escritora alsaciana que vivió 5 años en la Argentina (1856-1862) cuenta así la fiesta del 25 de Mayo, aniversario de la Revolución de Mayo:

Estoy al lado de doña Mercedes de L, una mujer todavía hermosa y cuya hija de quince años es una de las jóvenes más bellas del baile. Doña Mercedes me hablaba de la fiesta cuando, de repente, detrás del sillón oigo el llanto de un bebé; me doy vuelta rápidamente y veo a una india con su pequeño envuelto en una chalina, apoyado sobre su hombro como acostumbraban las mujeres del desierto. Esta india tiene la tez bronceada, la figura triste, la boca entreabierta, con una suerte de gesto desdeñoso, los dientes blancos, la mirada melancólica, los cabellos descuidados cayendo rectos como si fueran crin; una manta enredada 
como falda, la cabeza del niñito por encima del hombro, ella se mantiene derecha y noble detrás del sillón de Doña Mercedes, quien, drapeada en un magnífico vestido de brocado, resplandecía bajo sus puntillas de perlas y brillantes. (77)

Dos mujeres que vivieron la misma época están presentadas aquí en proximidad, habitando el mismo espacio y el mismo tiempo, y ambas son descriptas de manera paralela: hijo/a, ropa, aplomo/elegancia. La mirada de la viajera europea es atraída por el llanto del niño — lo no verbal que interrumpe la conversación de las mujeres blancas.

Beck-Bernard dice luego:

Este contraste, todavía novedoso, me llamó la atención de una manera que no podría describir. Era el lujo de la civilización al lado de la barbarie, como Santa Fe está al lado del Chaco. Estas dos mujeres personificaban, de manera sorprendente, dos razas que trescientos años de luchas han dejado enemistadas y que permanecerán irreconciliables, como siempre lo son los pueblos desposeídos frente a los pueblos invasores. (77, el subrayado es nuestro)

Esa imposibilidad de la descripción — «no podría describir» dice Beck-Bernard—, ese quiebre de la palabra, es nuestra entrada al texto y es también parte del archivo hospitalario. Quizá nosotras podamos dar con la palabra para describir eso que Beck-Bernard no puede: desigualdad, colonialismo, diferencia de clases, explotación. Hay algo que excede lo que la autora puede decir y eso es lo más productivo. La novedad presentada en el texto es la irreconciabilidad: el ancla de una inquietud, el amparo a un texto del futuro. La presencia de las tres mujeres juntas es de por sí testimonio. El relato de la viajera europea da cuenta de algo que no se puede codificar y que nosotras tampoco podemos explicar más que para decir «acá estuvo».

Emerge en el texto la dignidad de la mujer indígena, su noble postura. Beck-Bernard está usando códigos de la época (algunos crueles y racistas) para describirla. Sin embargo, lo que introduce en la postura de la indígena (su nobleza, su posición erguida) es parte del como si del que hablamos al principio. La mujer indígena existe más allá de la presencia de Mercedes de L. Imaginemos la escena en un escenario en claroscuro: iluminamos a Mercedes y vemos a dos mujeres blancas hablando, la mirada de Mercedes enfocada en su hija de 15 años (y en esto una serie de posibles lecturas). Oscurezcamos ahora esa escena y veamos la que está detrás del sillón: una mujer indígena con un bebé en el rebozo. La escena es de ternura: madre e hijo o hija están muy cerca uno del otro, la madre está parada con nobleza. Está ahí ocupando su propio espacio, como si le perteneciera, en realidad le pertenece. Tiene su narrativa propia en este espacio, donde la contrapartida de la palabra civilización es invasión. En la cita de Beck-Bernard leemos la presencia de esta mujer indígena como el lugar del como si. ¿Cuál es el lugar del como si? Es el espacio no asignado, tomado sin permiso. Es el lugar de las sufragistas en la calle, el de las Madres de Plaza de Mayo en la plaza. Es el lugar desde el cual se ejercen las tretas del débil.

La función de archivo de estos textos permite desvincularlos de la voz narrativa. ${ }^{5}$ No tienen mucha importancia en este sentido los quiebres en el discurso de Beck-Bernard, los espacios en que su mirada tiene marcas de clase o de raza sino esta ventana que nos ofrece a una subalternidad que podemos leer. Ana Peluffo, por ejemplo, apunta el registro ahogado que hace Clorinda Matto de Turner sobre la presencia de la violencia sexual y la violación en la mita en Perú a mediados 
del siglo XIX. Resumida en una frase: «las mujeres que entran de mita salen mirando el suelo»; se registran, afirma Peluffo, a través de sus efectos somáticos (la mirada baja), las emociones que despiertan los acosos de sus patrones. ${ }^{6}$

En Yo nunca te prometí la eternidad, la escritora argentina Tununa Mercado revela cómo moldea en su propia experiencia como exiliada argentina en México la subjetividad de la protagonista de su novela, una mujer judía que huye al sur de Francia cuando los nazis ocupan París.

Dice Mercado: «había superpuesto, como si calcara, la propia condición de los exiliados, sobre la suerte de esos perdidos en la noche» (213). Para escribir esta novela que retoma la historia de una mujer que vivió una experiencia traumática, Mercado hace un trabajo de investigación exhaustivo pero acude a su propia experiencia para darle textura a la vida íntima de su protagonista. ${ }^{7}$ Lo que se llena con la experiencia personal no son los vacíos del archivo sino lo que nunca se archivó. Y la fuerza enorme que tiene el trabajo de Mercado está en la exhibición de esta estrategia, en la revelación ante sus lectoras del procedimiento. De ese modo se logra una determinada desnudez del texto, similar a la desnudez de Jesusa al final de la performance. Una desnudez que invita nuevamente al vestido, al artificio, al lenguaje, a un nuevo modo de intervención cultural.

\section{Notas}

1 De esta manera leen Freud y Derrida el pasaje bíblico que refiere al posible asesinato de Moisés: a través del recurso al bloqueo divino de la nube que detuvo las piedras dirigidas a él, algo que podría haber efectivamente sucedido se convierte en un mero intento.

2 Tomamos el término de Michael Rothberg que propone «against the framework that understands collective memory as competitive memory —as a zero-sum struggle over scarce resources- I suggest that we consider memory as multidirectional: as subject to ongoing negotiation, cross-referencing, and borrowing; as productive and not privative» (3).

3 La hija de Freud en la obra de Sabina Berman atiende «pequeños pacientes» en un consultorio al que se accede a través de una pequeña puerta que está al lado de la gran puerta del consultorio del padre psicoanalista. En Dora es igualmente factible la violación, la violencia, el disciplinamiento brutal. Sara
Ahmed ha estudiado la genealogía de la infelicidad en textos escritos por mujeres en The Promise of Happiness (2010).

4 En The Civil Contract of Photography, capítulo 5. Ver también su trabajo reciente Azoulay, A. (2018).

5 Como lo ha mostrado Ana Peluffo, los textos escritos por las mujeres en el siglo XIX son muy inestables y si nos anclamos en la voz autoral como única corremos el riesgo de pasar por alto lecturas muy ricas (21).

6 Dice Peluffo, «bajaban la mirada abrumadas por el peso de un delito sexual». En la breve oración «las mujeres que entran de mita salen mirando al suelo» Matto denuncia lo que no se puede decir en 1889 (violencia sexual, violación) (21).

7 Afirman Françoise Lionnet y Emmanuel Bruno Jean François, «As humanists we are interested in the small narratives and significant details that give us the texture of human interactions in the contact zones of migratory flows» (1222-1223).

\section{Referencias bibliográficas}

Ahmed, S. (2010). The Promise of Happiness. Durham: Duke University Press.

Azoulay, A. (2008). The Civil Contract of Photography. Londres: Zone.

(2018). The Natural History of Rape. Journal of Visual Culture, 17(2), 166-176. 
Beck-Bernard, L. (2013). El río Paraná. Cinco años en la República Argentina. Torre, C. (Ed.). Paraná: Eduner. Traducción de Cecilia Beceyro.

Berman, S. (2001). Feliz nuevo siglo doktor Freud. México: El milagro, Conaculta.

Clément, C. (1997). L’Ópera ou la défaite des femmes. Paris: Grasset.

De La Cruz, J.I. (1988). Obras completas. Plancarte, A.M. (Ed.). Vol. 1. México: Fondo de Cultura Económica.

Derrida, J. (1997). Mal de archivo. Una impresión freudiana. Valladolid: Trotta. Traducción de Paco Vidarte.

Freud, S. (1907). Delirios y sueños en la Gradiva de W. Jensen. En Obras completas. Vol. 3. Buenos Aires: Amorrortu, 1996.

Freud, S. (1996). Obras completas. Vol. 3. Buenos Aires: Amorrortu.

Lionnet, F. y Jean François, E.B. (2016). Literary Routes: Migration, Islands and the Creative Economy. PMLA, 131(5), 1222-1238.

Ludmer, J. (1984). Tretas del débil. En González, P. y Ortega, E. (Eds.). La sartén por el mango. Encuentro de escritoras latinoamericanas. Río Piedras: Huracán, 47-54.

Manoff, M. (2004). Theories of the Archive from Across the Disciplines. Libraries and the Academy, 4(1), 9-25.

Mercado, T. (2005). Yo nunca te prometí la eternidad. Buenos Aires: Planeta.

Peluffo, A. (2017). En clave emocional. Cultura y afecto en América Latina. Buenos Aires: Prometeo.

Pratt, M.L. (2015). Afterword: Figures, Texts, and Moments. En Rodríguez, I. y Szurmuk, M. The Cambridge History of Latin American Women's Literature. Cambridge: Cambridge University Press, 559-573.

Rothberg, M. (2009). Multidirectional Memory: Remembering the Holocaust in the Age of Decolonization. Stanford: Stanford University Press. 